\title{
Pengaruh Sport Massage Terhadap Kecemasan Olahraga Atlet Futsal Undikma
}

\author{
${ }^{1}$ Arif Yanuar Musrifin, ${ }^{2}$ Andi Anshari Bausad \\ Program Studi Pendidikan Olahraga dan Kesehatan, Fakultas Ilmu Keolahragaaan dan \\ Kesehatan Masyarakat dan , Universitas Pendidikan Mandalika \\ Email: arifyanuarmusrifin.ikipmataram.ac.id
}

\begin{abstract}
Abstrak. Penelitian ini dilatar belakangi oleh atlet Futsal putra UNDIKMA seringkali merasa tegangan sebelum bertanding, dampak dari ketengangan terhadap penampilan keterampialan gerak pada atlet, atara lain menimbukan kecemasan, emosi, ketegangan pada otot, kelenturan, dan koordinasi. Dengan demikian perlu pemberian massage sebelum pertanding agar pemanin lebih tenang dan tidak tegang sehingga Sport massage merupakan salah satu alternatif untuk membuat pemain merasa rileks, tenang, menurukan kecemasan dan mempercepat aliran peredaran darah. Adapun yang menjadi masalah dalam penelitian ini adalah "apakah ada pengaruh sport massage terhadap kecemasan olahraga pada atlet futsal UNDIKMA tahun 2020. Penelitian ini bertujuan untuk mengetahui ada atau tidaknya pengaruh sport massage terhadap kecemasan olahraga pada atlet futsal UNDIKMA tahun 2020. Penelitian ini merupakan penelitian eksperimen. Penelitian ini menggunakan dua variabel yang terdiri dari satu variable bebas (sport massage) dan satu variable terikat yaitu kecemasan olahraga. Populasi yang digunakan dalam penelitian ini adalah seluruh atlet futsal UNDIKMA tahun 2020 sebanyak 10 pemain. Tehnik sampling yang digunakan yaitu tehnik studi populasi. Teknik pengambilan data menggunakan metode perbuatan yaitu test dan pengukuran dengan instrument pemberian angket kecemasan olahraga. Teknik analisis data menggunakan analisis uji $\mathrm{t}$ dengan taraf signifikan $5 \%$. Karena $t$ hitung $>t$ tabel $(8,476>1,833)$. Keseimpulan penelitian ini menunjukan bahwa ada pengaruh sport massage terhadap kecemasan olahraga pada atlet futsal UNDIKMA tahun 2020.
\end{abstract}

Kata Kunci: Sport Massage, Kecemasan Olahraga, Futsal

\section{PENDAHULUAN}

Olahraga adalah gerak manusia yang dilakukan secara sadar, dengan cara-cara efektif yang berkaitan dengan usaha-usaha untuk memelihara serta meningkatkan kualitas manusia, dengan memandang manusia sebagai salah satu kesatuan psiko fisik yang kompleks. Aktivitas olahraga yang dilakukan bertujuan untuk meningkatkan kualitas fisik sumber daya manusia, apabila dilakukan secara benar dan teratur. Setalah melakukan aktivitas olahraga kita sering merasa lelah,otot pegal dan sakit. Untuk mengatasi rasa sakit atau pegal tersebut, tubuh perlu pemulihan yang cukup sehingga menjadi segar kembali. Cara untuk mempercepat pemulihan ada bermacammacam, seperti : istirahat aktif, akupuntur, massage, dan lain-lain.

Dari semua cara di atas, massage kini dipandang sebagai cara yang paling berhasil untuk relaksasi akibat kelelahan atau rasa pegal yang dialami setelah melakukan aktivitas bagi kebanyakan orang. Pada masa ini bukti telah mendukung posisi massage yang telah dipraktekkan oleh beberapa kelompok orang di dunia. Para arkheolog telah menemukan artefak-artefak yang menunjukan penggunaan massage disejumlah wilayah di dunia. Meskipun tidak ada bukti pre-historis langsung yang menjelaskan penggunaan massage untuk alasan-alasan medis, bukti tidak langsung sangat jelas menunjukan kaitan massage dengan medis. Lukisan di gua eropa pada abad 15000 SM misalnya, menunjukkan adanya penggunaan sentuhan sebagai terapi (Soemardiawan dan Mujriah, 2014: 1).

Massage sebenarnya ada berbagai macam tetapi yang paling dikenal adalah Sport Massage. Sport massage adalah manipulasi dengan menggunakan tangan, untuk menstimulasi, merelaksasi serta mengurangi ketegangan, dan kelelahan pada atlet maupun pemain yang telah melakukan kegiatan olahraga. Sport massage dibutuhkan bukan hanya oleh atlet (professional dan amatir) tapi juga oleh mereka yang memiliki 
aktivitas non olahraga tetapi banyak memforsir kerja tubuh, misalnya ibu yang sering menggendong anak yang masih kecil dan pekerja kantor yang sering kali duduk di depan komputer dalam waktu yang lama. Sport massage berpengaruh menurunkan kecemasan, melancarkan peredaran darah, massage merupakan manipulasi dari struktur jaringan lunak yang diterapkan pada tubuh manusia untuk menimbulkan rasa tenang, nyaman, rileks, dan mengurangi rasa sakit.

Sport massage memiliki macammacam manipulasi dan pengaruhnya. Manipulasi atau pegangan yang dilakukan oleh seorang masseur dilakukan dengan tekanan yang cukup disesuaikan dengan kondisi pasien dan penuh perasaan sehingga mendatangkan rasa nyaman pada pasien yang bersangkutan (Joesoef Roepajadi, 2009:6). Dilihat dari urutan teknik manipulasinya sport massage dimulai dari effleurage, patrissage, friction, shaking, tapotement, walken, vibration, skin rolling, stroking. Dilihat dari jenis manipulasinya sport massage ini mempunyai manfaat terhadap tubuh, Karena merupakan massage relaksasi maka diharapkan mampu menurunkan kecemasan olahraga seseorang saat bertanding.

Kecemasan anxiety adalah salah satu gejala psikologi yang indentik dengan perasaan negatif (Apta Mylsidayu. 2014 : 42). Kecemasan olahraga mengambarkan perasaan atlet bahwa sesuatu yang tidak di kehendaki akan terjadi. Hal yang di kehendaki misalnya ketegangan sebelum bertanding dampak dari ketengangan terhadap penampilan keterampialan gerak pada atlet, atara lain menimbukan kecemasan, emosi, ketegangan pada otot, kelenturan, dan koordinasi. Dengan demikian perlu pemberian massage sebelum pertanding agar pemanin lebih tenang dan tidak tegang sehingga Sport massage merupakan salah satu alternatif untuk membuat pemain merasa rileks, tenang, menurukan kecemasan dan mempercepat aliran peredaran darah.
Menurut hasil observasi yang sudah dilakukan oleh peneliti selama ini bahwa pemain futsal putra UNDIKMA seringkali merasa cemas, gelisah dan tidak tenang dalam menghadapai pertandingan. Hal tersebut terjadi karena adanya tekanantekanan secara kejiwaan ketika bermain dan sifat kompetisi olaharaga yang di dalamnya penuh dengan perubahan dari keadaan permainan ataupun kondisi alam yang membuat menurunnya kepercayaan diri dari penampilan. Keadaan tersebut jelas sangat berpengaruh terhadap kondisi fisik dan psikologis.

Komponen biomotor merupakan sebuah prasarat yang sangat dibutuhkan dan diperlukan dalam setiap usaha peningkatan prestasi atlet. Komponen biomotorik meliputi Strength, Endurance, Speed, Coordination and Flexibility. Seorang pelatih dapat memilih dan memutuskan tentang komponen kondisi fisik yang direncanakan dan diberikan bagi atletnya untuk mencapai prestasi pada cabang olahraga yang dilatihnya. Komponen biomotorik dasar harus dimiliki secara maksimal oleh setiap atlet dalam cabang olahraga apapun. Komponen biomotorik dasar pemain futsal memerlukan kecepatan dan mobilitas gerak yang dikombinasikan dengan agilitas (kelincahan) yang biasanya dimanfaatkan untuk menyerang dan bertahan dengan baik (Anshari \& Yanuar, 2016). Olahraga futsal sendiri merupakan olahraga permainan yang dilakukan dengan tempo tinggi, fisik yang prima diperlukan saat berlari, bergerak mencari ruang, serta dalam mengantisipasi lawan saat kondisi memungkinkan untuk melakukan pertahanan menggunakan badan (Asriady, 2014).

Peranan Sport massage dalam dunia olahraga sangat penting dalam meningkatkan prestasi atlet. Hasil penelitian yang sudah dilaksanakan sebelumnya, menunjukan bahwa metode sport masase sebagai pemulihanan pasif dapat meningkatkan kapasitas daya tahan maksimal (vo2max) atlet futsal UNDIKMA (Yanuar \& Anshari, 2018). Berdasarkan uraian tersebut tujuan 
dari penelitian ini adalah untuk melakukan penelitian tentang "pengaruh sport massage terhadap kecemasan olahraga atlet futsal UNDIKMA tahun 2020.

\section{METODE}

Penelitian ini merupakan penelitian eksperimen yaitu suatu penelitian yang peneliti sengaja membangkitkan timbulnya sesuatu kejadian atau keadaan, kemudian diteliti bagaimana akibatnya (Darmadi, 2013:40). Pendekatan yang digunakan dalam penelitian ini yaitu kuantitatif. Pendekatan kuantitatif adalah data yang dinyatakan dalam bentuk angka.

Desain penelitian yang digunakan pada penelitian ini adalah "one group pretest-posttest design". Desain tersebut digambarkan sebagai berikut :

\begin{tabular}{|lll|}
\hline $\mathrm{T}_{1}$ & $\mathrm{X}$ & $\mathrm{T}_{2}$ \\
\hline
\end{tabular}

Gambar 3.1: Desain Penelitian

(Sumber: Hulfian, 2014:38)

Keterangan :

$$
\begin{aligned}
\mathrm{T}_{1} & =\text { Nilai Pretest (Sebelum Diberi } \\
& \text { Perlakuan) } \\
\mathrm{X} & =\text { Perlakuan } \\
\mathrm{T}_{2} & =\text { Nilai Posttest (Setelah Diberi } \\
& \text { Latihan) }
\end{aligned}
$$

$\mathrm{T}_{1}=$ Merupakan pengambilan tingkat kecemasan atlet futsal UNDIKMA sebelum di berikan perlakukan sport masase dalam 3 pertandingan tingkat mahasiswa atau umum yang diikuti di NTB, X merupakan perlakukan dengan pemberian sport masase pada atlet futsal UNDIKMA selama latihan 1 minggu 3 kali latihan dan pemberian masase pada saat pertandingan sebanyak 3 kali pertandingan tingkat mahasiswa atau umum yang diikuti di NTB. $\mathrm{T}_{2}$ merupakan pengambilan tingkat kecemasan atlet futsal UNDIKMA pemberian masase pada saat pertandingan sebanyak 3 kali pertandingan tingkat mahasiswa atau umum yang diikuti di NTB.

Subyek yang menjadi penelitian ini adalah atlet futsal UNDIKMA sebanyak 10 pemain, untuk tenaga masseure juga sebanyak 10 yang merupakan mahasiswa FIKKM UNDIKMA yang telah menempuh mata kuliah masase dengan mendapatkan rekomendasi dari dosen pengampu mata kuliah masase.

Instrumen dalam penelitian berupa angket tentang kompenen kecemasan olahraga ( Nyak Amir jurnal penelitan dan evaluasi pendidikan pengembangan alat ukur kecemasan olahraga ) yang meliputi: Faktor motorik, factor afektif, factor somatik dan factor kognitif. Selanjutnya komponen masing-masing indikator tersebut dibuat pertanyaan atau pernyataan (Jurnal Penelitian dan Evaluasi pendidikan, Tahun 2010 Nomor 1.

Untuk mengetahui data tentang kecemasan olahraga digunakan instrument berupa angket dalam bentuk tertutup dan secara langsung dimana responden (subyek) penelitian tinggal memilih jawaban yang sesuai dengan keadaan dirinya. Angket ini terdiri atas 4 alternatif pilih jawaban yaitu: a, $\mathrm{b}$, c, dan d dengan pemberian skor adalah sebagai berikut: "untuk pilihan (a) selalu yaitu akan diberi skor 4 (empat), (b) sering yaitu akan diberi skor 3 (tiga), (c) jarang sekali yaitu akan diberi skor 2 (dua) dan (d) tidak pernah yaitu akan diberi skor 1 (satu) (Sugiyono, 2016: 162).

Dalam penelitian ini Alternatif jawaban responden telah ditentukan dengan menggunakan skala Likert yakni; "Sangat Sesuai (SS), Sesuai (S), Agak Sesuai (AS), dan Tidak Sesuai (TS)." Pemberian skor untuk skala kecemasan olahraga disesuaikan dengan jawaban butir pertanyaan, yakni: $\mathrm{SS}=4, \mathrm{~S}=3, \mathrm{AS}=2, \mathrm{TS}=1$. Penentuan tingkat kecemasan tes didasarkan pada skor yang tercantum dibawah ini.

Tabel 1. Klasifikasi Tingkat Kecemasan Berdasarkan Skor Setiap Skala

\begin{tabular}{|c|c|c|c|}
\hline \multicolumn{4}{|c|}{ Tingkat Kecemasan olahraga } \\
\hline Rendah & $\begin{array}{c}\text { Angak } \\
\text { rendah }\end{array}$ & $\begin{array}{c}\text { Agak } \\
\text { tinggi }\end{array}$ & Tinggi \\
\hline $1-22$ & $23-44$ & $45-66$ & $67-88$ \\
\hline
\end{tabular}

Tehnik Analisis data, metode pengolahan data yang digunakan adalah metode analisis statistik, karena data yang 
diperoleh bersifat kuantitatif yang berupa angka-angka didalam analisis statistik data yang diperoleh terlebih dahulu harus dibuktikan kebenaranya dan kevaliditasannya. Untuk keperluan tersebut penulis menggunakan rumus "t-tes" dengan penjabaran sebagi berikut :

$$
t=\frac{\sum \mathrm{D}}{\frac{\sqrt{N \cdot \sum D^{2}-\left(\sum \mathrm{D}\right)^{2}}}{(\mathrm{~N}-1)}}
$$

(Hulfian, 2014: 70)

Keterangan:

$\mathrm{D}=$ Perbedaan setiap pasangan skor (post test-pre test)

$\mathrm{N}=$ Jumlah sampel yang digunakan

\section{HASIL PENELITIAN}

Penelitian ini guna mendapatkan data terkini tentang kemampuan para atlet futsal putra UNDIKMA tersebut. Dalam penelitian ini menggunakan dua metode pengumpulan data yaitu: (1) metode tes perbuatan digunakan untuk mendapatkan data tentang kecemasa olahraga. Selama melaksanakan tes perbuatan peneliti. (2) metode dokumentasi yaitu metode yang digunakan untuk mendapatkan data tentang jumlah subjek dan nama subjek yang diteliti. adapun jumlah subjek yang diteliti sebanyak 10 orang tim UKM futsal putra UNDIKMA.

Berdasarkan perlakuan yang diberikan selama 6 minggu dengan frekuensi 3 kali seminggu, perlakuan menggunakan sport massage dengan memberikan pengaruh yang signifikan terhadap kecemasan olahraga, ini terbukti dari hasil penelitian yang dilakukan. Bahwa sport massage dapat menurunkan kecemasan pada atlet futsal UNDIKMA.

Tabel 2. Hasil pre test tingkat kecemasan olahraga

\begin{tabular}{|c|c|c|}
\hline No & Nama Pemain & $\begin{array}{c}\text { Tingkat } \\
\text { kecemasan } \\
\text { olahraga }\end{array}$ \\
\hline 1. & A & 43 \\
\hline 2. & B & 57 \\
\hline 3. & C & 56 \\
\hline 4. & D & 73 \\
\hline
\end{tabular}

\begin{tabular}{|c|c|c|}
\hline 5. & E & 65 \\
\hline 6. & F & 73 \\
\hline 7. & G & 74 \\
\hline 8. & H & 69 \\
\hline 9. & I & 59 \\
\hline 10. & J & 52 \\
\hline
\end{tabular}

Tabel 3. Selanjutnya Hasil post test tingkat kecemasan olahraga.

\begin{tabular}{|c|c|c|}
\hline No & $\begin{array}{c}\text { Nama } \\
\text { Pemain }\end{array}$ & $\begin{array}{c}\text { Tingkat kecemasan } \\
\text { olahraga }\end{array}$ \\
\hline 1. & A & 32 \\
\hline 2. & B & 26 \\
\hline 3. & C & 39 \\
\hline 4. & D & 34 \\
\hline 5. & E & 36 \\
\hline 6. & F & 35 \\
\hline 7. & G & 30 \\
\hline 8. & H & 35 \\
\hline 9. & I & 33 \\
\hline 10. & J & 34 \\
\hline
\end{tabular}

Berdasarkan tabel diatas dapat kita lihat bahwa ada penurunan tingkat kecemasan olahraga pada atlet UKM futsal putra UNDIKMA. Dari 10 atlet tingkat kecemasanya masuk dalam katagori agak rendah setelah di berikan perlakuan berupa pemberian sport massage.

Berdasarkan data yang telah dikumpulkan perlu disusun tabel kerja untuk mendapatkan nilai-nilai. Sesuai dengan rumus yang digunakan, makah tabel kerja yang dibutuhkan adalah tabel kerja untuk menentukan komponen-komponen dalam rumus.tabel kerja yang dimaksud adalah sebagai berikut. 
Tabel 4. Membuat Table Kerja

\begin{tabular}{|c|c|c|c|c|}
\hline \multirow{2}{*}{ No } & \multicolumn{2}{|c|}{$\begin{array}{c}\text { Tes kecemasan } \\
\text { olahraga }\end{array}$} & \multirow{2}{*}{ D } & \multirow{2}{*}{$\mathbf{D}^{\mathbf{2}}$} \\
\cline { 2 - 4 } & $\begin{array}{c}\text { Pre test } \\
\left(\mathbf{T}_{\mathbf{1}}\right)\end{array}$ & $\begin{array}{c}\text { Post test } \\
\left(\mathbf{T}_{\mathbf{2}}\right)\end{array}$ & & \\
\hline 1 & 43 & 32 & 11 & 101 \\
\hline 2 & 57 & 26 & 31 & 961 \\
\hline 3 & 56 & 39 & 17 & 289 \\
\hline 4 & 73 & 34 & 39 & 1521 \\
\hline 5 & 65 & 36 & 29 & 841 \\
\hline 6 & 73 & 35 & 38 & 1444 \\
\hline 7 & 74 & 30 & 44 & 1936 \\
\hline 8 & 69 & 35 & 34 & 1156 \\
\hline 9 & 59 & 33 & 26 & 676 \\
\hline 10 & 52 & 34 & 18 & 324 \\
\hline Jml & $\mathbf{6 2 1}$ & $\mathbf{3 3 4}$ & $\mathbf{2 8 7}$ & $\mathbf{9 2 6 9}$ \\
\hline
\end{tabular}

Dengan demikian, untuk memasukan data ke dalam rumus,langkah terakhir dalam menghitung data-data dengan statistik (rumus-rumus) adalah dengan menghitung nilai perbandingan antara tes awal (pre-test) dan tes akhir (post-test) dengan menggunakan rumus " $\mathrm{t}$ " test sebagai berikut:

$$
\begin{gathered}
t=\frac{\sum D}{\sqrt{\frac{N \cdot \sum D^{2}-\left(\sum D\right)^{2}}{N-1}}} \\
t=\frac{287}{\sqrt{\frac{10(9269)-(287)^{2}}{10-1}}} \\
t=\frac{287}{\sqrt{\frac{92690-82369}{9}}} \\
t=\frac{287}{\sqrt{\frac{10321}{9}}} \\
t=\frac{287}{\sqrt{1146.78}} \\
t=\frac{287}{33.86} \\
t=8,476
\end{gathered}
$$

Setelah kita mendaptkan nilai t-hitung, kemudian t-hitung dibandingkan dengan $\mathrm{t}$ tabel dengan $\mathrm{db}(\mathrm{N}-1=10-1=9)$ pada taraf signifikan $5 \%$, maka t-tabel menunujukan angka 1,833. Sedangkan t-hitung menunjukan angka 8,476. Untuk menolak hipotesis Nihil (Ho) atas dasar signifikan $5 \%$ sampai diperlukan nilai t-hitung sama atau lebih besar dari t-tabel. Bila kita membandingkan nilai t-hitung sebesar 8,476 dengan t-tabel 1,833 dengan taraf signifikan 5\% maka t-hitung lebih besar dari t-tabel $(8,476>1,833)$, dengan demikian hipotesis nihil (Ho) ditolak dan hipotesis alternatif (Ha) diterima, berarti hasilnya signifikan.

\section{PEMBAHASAN}

Dalam permainan futsal pemain pasti mempunyai kekurangan, dan kekurangan itu menjadi tugas untuk pelatih agar bisa menutupi kekurangan tersebut. Dari hasil pelaksanaan tes awal terdapat kekurangan pada pemain seperti merasa tegang sebelm bertanding dampak dari ketengangan terhadap penampilan keterampialan gerak pada atlet, atara lain menimbukan kecemasan, emosi, ketegangan pada otot, kelenturan, dan koordinasi. Dengan demikian perlu pemberian massage sebelum pertanding

Menurut Bambang Priyonoadi ( 2008:5-6) tujuan dan manfaat sport massage secara umum:

a. Melancarkan peredaran darah, terutama dorongan terhadap darah veneus atau darah yang menuju ke jantung. Kelancaran peredaran darah ini selanjutnya akan mempercepat proses pembuangan sisa-sisa pembakaran dan penyebaran sari makanan ke jaringanjaringan tubuh.

b. Merangsang persarafan, terutam saraf tepi ( perifer ) untuk meningkat kepekaan terhadap rangsang.

c. Meningkatkan ketegangan otot dan kekenyalan otot untuk mempertinggi daya kerjanya, sport massage akan membantu proses kontraksi otot yaitu penegangan dan pemendekan otot dengan maksimal.

Dari tujuan dan manfaat sport massage yang telah diuraiakan di atas, sejalan dengan hasil penelitian yang sudah dilakukan bahwa pemberian sport massage dapat menggurangi tingkat kecemasan pemain. 
Setelah melakukan penghitungan data kecemasan olahraga pada atlet futsal UNDIKMA maka peneliti dapat mengetahui bahwasanya pemberian sport massage pada pemain futsal setelah latihan dapat menurunkan kecemasan olahraga. Dari data di atas juga kita dapat mengetahui bahwa dari 9 atlet yang memiliki tingkat kecemasan yang tinggi pada tes awal, pada tes kedua tingkat kecemasan olahraga berkurang setelah diberikan sport massage. Hal ini dapat dijadikan tolak ukur sport massage memiliki pengaruh yang sangat signifikan terhadap penurunan kecemasan olahraga.

Tabel 5. Rekapitulasi tiap butir angket dari keseluruhan sampel penelitian.

\begin{tabular}{|c|c|c|}
\hline $\begin{array}{c}\text { Soal } \\
\text { Nomor }\end{array}$ & Total & Rata- Rata \\
\hline 1 & 41 & 4,1 \\
\hline 2 & 33 & 3,3 \\
\hline 3 & 36 & 3,6 \\
\hline 4 & 42 & 4,2 \\
\hline 5 & 36 & 3,6 \\
\hline 6 & 45 & 4,5 \\
\hline 7 & 44 & 4,4 \\
\hline 8 & 41 & 4,1 \\
\hline 9 & 46 & 4,6 \\
\hline 10 & 42 & 4,2 \\
\hline 11 & 42 & 4,2 \\
\hline 12 & 49 & 4,9 \\
\hline 13 & 38 & 3,8 \\
\hline 14 & 46 & 4,6 \\
\hline 15 & 47 & 4,7 \\
\hline 16 & 50 & 5 \\
\hline 17 & 46 & 4,6 \\
\hline 18 & 49 & 4,9 \\
\hline 19 & 42 & 4,2 \\
\hline 20 & 53 & 5,3 \\
\hline 21 & 43 & 4,3 \\
\hline 22 & 44 & 4,4 \\
\hline
\end{tabular}

Berdasarkan tabel rekapitulasi tiap butir angket dari keseluruhan sampel penelitian di atas tingkat kecemasan olahraga dapat di lihat dari nilai rata-rata setiap butir anget yang di berikan. Dari nilai rata-rata di atas terdapat 5 butir soal yang menjadi permasalahan kecemasan olahraga atlet futsal putra UNDIKMA dengan nilai ratarata paling tinggi diantranya sebagai berikut :

1. Butir soal nol 20, dengan nilai rata-rata 5,3 pernyataan tesnya adalah saya sering minum air saat menghadapi pertandingan.

2. Butir soal nol 16 , dengan nilai rata-rata 5 pernyataan tesnya adalah saya sering jalan mondar- mandir saat menghadapi pertandingan.

3. Butir soal nol 12 dan 18 , dengan nilai rata-rata 4,9 pernyataan tesnya adalah saya selalu ingin buang air kecil saat menghadapi pertandingan dan bandan saya lesu saat menghadapi pertandingan.

4. Butir soal nol 15, dengan nilai rata-rata 4,7 pernyataan tesnya adalah pernafasan saya tidak teratur saat menghadapi pertandingan.

5. Butir soal nol 9 dan 17 , dengan nilai rata-rata 4,6 pernyataan tesnya adalah saya mengalami ketegangan saat mengahadapi pertandingan dan saya sering menggaruk-garuk kepala saat menghadapi pertandingan.

Kecemasan dapat timbul kapan saja, dan salah satu penyebap terjadinya kecemasan adalah ketengangan yang berlebihan yang berlangsung lama (Apta Mylsidayu 2014 :42). Ketegangan yang berlebihan dan berlangsung relative lama dapat menyebabkan kecemasan.( Prof. Dr. H.J.S. Husdarta, M.Pd. 2014 :73). Kecemasan dalam olahraga yang paling umum di lingkungan olahraga kompetitif dan juga bisa disebut stress kompetitif. Kurangnya Konsensus membuatrnya sulit untuk secara jelas mendefinisikan kecemasan dan stress dalam olahraga. Kecemasan, atau merasa fisik dan mental cemas dapat hadir dalam cara yang berbeda, seperti ketakutan dan gugup, tetapi memiliki penyebab yang mendasari; stimulasi sistem saraf simpatik. Sistem saraf simpatik adalah persis seperti itu, sistem saraf simpatif untuk kedua suasana hati kita dan lingkungan kita. Kecemasan adalah reaksi alami terhadap ancaman di lingkungan dan bagian dari persiapan untuk"fight or flight" respon. (Stephani Yane jurnal pendidikan olahraga, Vol. 2, No. 2, Desember 2013). Secara umum, kecemasan dapat dibagai dalam dua kategori, yakni state anxiety dan triait anxiety, ketakuatan yang tidak proposonal terhadap suatu situasi tertentu di sebut dengan state anxiety. Jenis kecemasan ini merupakan kondidi emosi yang bersifat 
semantara dan berlangsung untuk suatu situasi tertentu saja. Jenis kecemasan berikutnya adalah Jenis kecemasan berikutnya adalah trait anxiety, jenis kecemasan yang lebih menetap dan menyebar ke berbagai aspek kehidupan individu. Individu merasa cemas, kapan dan sehingga timbul rasa khawatir dan tegang.

Dari uraian di atas dapat kita lihat masih ada kecemasan olahraga pada atlet futsal putra UNDIKMA pada saat menghadapi pertandingan, lebih khususnya pada 5 pernyataan angket di atas, maka dari itu harus ada penelitian selanjutnya mengenai tingkat kecemasan atlet futsal putra UNDIKMA lebih kepada cara penenganan secara psikoligis atlet.

\section{KESIMPULAN}

Kesimpulan penelian ini adalah bahwa sport massage memiliki pengaruh yang sangat signifikan terhadap penurunan kecemasan olahraga pada atlet futsal putra UNDIKMA tahun 2020.

\section{SARAN}

Gagasan selanjutnya dari penelitian ini adalah bagaimana meningkatkan ketenangan, percaya diri atau psikologi atlet futsal putra UNDIKMA malalui program latihan yang menyentuh aspek psikologis atlet yang di susun oleh pelatih untuk menangani kecemasan atlet saat bertanding.

\section{DAFTAR PUSTAKA}

Anshari, Andi dan Yanuar. 2016. Efektifitas Penurunan Denyut Nadi Pemulihan Dengan Pemberian Masase Tehnik Shaking Pada Atlet Futsal IKIP Mataram.

Amir Nyak. 2012. Jurnal penelitian dan evaluasi pendidikan, pengembangan alat ukur kecemasan olahraga.

Darmadi, Hamid. 2013. Metode Penelitian Pendidikan. Bandung : Alfabeta.

Hulfian, Lalu. 2014. Penelitian Dikjas. Mataram : CV. Garuda Ilmu.
Mahmud Dimyati. M. 2018. Psikologi Suatu Pengantar. Yogyakarta : ANDI, Yogyakarta : BPFE

Mylsidayu Apta. 2014. Psikologi olahraga. Jakarta : Bumi Aksara

Priyonoadi, Bambang. 2008. Sport Massage. Yogyakarta : Fakultas Ilmu Keolagragaan Universitas Negeri Yogyakarta.

Roepajadi, Joesoef. 2009. Masase Olahraga. Fakultas Ilmu Keolahragaan Universitas Negeri Surabaya.

Soemardiawan., dan Mujriah. 2014. Massage Sport Segment. Mataram : Genius.

Husdarta, J .S. 2014. Psikologi olahraga. Bandung : Alfabeta

Yanuar, Arif M. 2012. Pengaruh Pembebanan Latihan Pada Denyut Nadi Terhadap Konsentrasi Atlet Bulutangkis Pusdiklat Citra Raya Unesa. Tesis S2. Universitas Negeri Surabaya.

Yane Stephani. 2013. Kecemasan dalam olahraga jurnal pendidikan olahraga, vol. 2, No, 2. 